\title{
Reduction in Hemodynamic Changes during Direct Laryngoscopy and Intubation by Intravenous Clonidine or Nalbuphine Premedication - A Comparative Evaluation
}

\author{
Manoranjan Kumar Bansal ${ }^{1}$, Kumkum Gupta ${ }^{2}$, Abhishake Kumar ${ }^{1}$, Salony Agarwal ${ }^{3}$, Deepak Sharma ${ }^{2}$, Ans M Baseer ${ }^{4}$ \\ ${ }^{1}$ Assistant Professor, Department of Anaesthesiology and critical care, ${ }^{2}$ Professor, Department of Anaesthesiology and critical care, ${ }^{3}$ Associate Professor, \\ Department of Anaesthesiology and critical care, ${ }^{4}$ Resident, Department of Anaesthesiology and critical care, Subharti Medical College, Swami Vivekanand \\ Subharti University, NH-58, By Pass Road, Meerut-UP, India.
}

\section{Abstract}

Background: Accentuated hemodynamic changes during direct laryngoscopy can be modified by appropriate premedication. The present study was aimed to comparatively evaluate the clinical efficacy of intravenous clonidine with nalbuphine premedication for reduction in hemodynamic changes during direct laryngoscopy and intubation. Subjects and Methods: Sixty adult consenting patients of ASA physical status I and II of either gender, were randomized into two equal groups of 30 patients each to receive either clonidine $(2 \mu \mathrm{g} / \mathrm{kg}) \mathrm{Group} \mathrm{I} \mathrm{or}$ nalbuphine $(0.2 \mathrm{mg} / \mathrm{kg})$ Group II, intravenously 10 minutes before induction. Anesthetic technique was standardised and direct laryngoscopy with intubation was facilitated with vecuronium bromide. Changes in heart rate, arterial blood pressure and ECG were recorded at baseline, after giving study drug, after laryngoscopy and intubation, then after at 1st, 2nd, 3rd, 5th, 10th, and 15th min of intubation and were noted as primary end points. Any side effects and complications were recorded as secondary end points. Results: After premedication in patients of comparable demographic profile, the fall in heart rate and blood pressure showed statistically significant difference between the groups. After laryngoscopy and intubation, the increase in mean heart rate and mean blood pressure occurred immediately in patients of both groups but persisted up to 5 to $7 \mathrm{~min}$ in patients of clonidine group and up to 10 minutes in patients of nalbuphine group with statistically significant difference between the groups. Conclusion: Intravenous clonidine premedication $(2 \mu \mathrm{g} / \mathrm{kg})$ could effectively reduce the hemodynamic changes during direct laryngoscopy and intubation when compared to intravenous nalbuphine $(0.2 \mathrm{mg} / \mathrm{kg})$, administered 10 min before induction.

Keywords: Clonidine, Direct Laryngoscopy and Intubation, Hemodynamic changes, Nalbuphine.

Corresponding Author: Prof (Dr) Kumkum Gupta, 108-109, Chanakyapuri, Shastri Nagar, Meerut-250004 U.P. India.

Received: December 2018

Accepted: December 2018

\section{Introduction}

The direct laryngoscopy and intubation is frequently performed to protect the airway from aspiration and allows unimpeded ventilation during general anaesthesia, but its clinical benefits are not without adverse effects due to increase in plasma catecholamine concentration, which causes transient and variable tachyarrhythmia and hypertension. ${ }^{[1]}$ These hemodynamic changes predispose the myocardium to ischemia that may be life threatening in cardiac compromised patients. Institution of appropriate premedication, smooth induction and rapid intubation can reduce these associated risks of hemodynamic changes.

An ideal anaesthetic drugs or technique should have a rapid onset of action, be safe and convenient to prepare and administer, besides minimizing the hemodynamic changes. It must be applicable to patients of all age groups, prevent impairment of cerebral blood flow and avoid awareness during anesthesia. It should not also affect the duration of anaesthesia and recovery characteristics.
Clonidine, partial $\alpha 2$ adrenergic agonist, decreases the sympathetic nervous system outflow from central nervous system to peripheral tissues and inhibit release of norepinephrine. It has sedative, analgesic and antihypertensive action in addition to reduction of the anaesthetic drugs requirement. ${ }^{[2,3]}$

Nalbuphine is a semi-synthetic agonist-antagonist opioid analgesic. It is agonist at kappa $(\kappa)$ receptors and acts as antagonist at $\mathrm{mu}(\mu)$ receptors. Nalbuphine not only suppresses the hemodynamic response but also provide intraoperative hemodynamic stability with prolonged duration of analgesia. Its potential safety in over dosage i.e. ceiling effect in respiratory depression, makes nalbuphine an ideal analgesic during anaesthesia. ${ }^{[4-6]}$

This prospective double blind randomized study was designed to comparatively evaluate the clinical efficacy of intravenous Clonidine versus Nalbuphine premedication on hemodynamic changes during direct laryngoscopy and intubation. 


\section{Subjects and Methods}

After approval from Institutional Ethical Committee and written informed consent, this prospective double blind randomized study was conducted on 60 patients of either gender aged between 18 to 58 years, weighing between 50 and $70 \mathrm{~kg}$ with American Society of Anaesthesiology (ASA) physical status I and II, and scheduled for elective surgical procedure under general anaesthesia.

\section{Selection criteria}

Patient suffering from cardio-pulmonary diseases, uncontrolled or untreated systemic hypertension, hepatic disease, renal disease, neurological disorder or endocrinal disease, morbidly obese patients, patients with known hypersensitivity or drug allergies, taking any medication, were excluded from the study. Patients with anticipated difficult airway, or may require more than one attempt for intubation or refused to participate in the study, were also excluded from the study.

Sixty adult patients were divided into two equal groups of 30 patients each, according to computer generated random number table. Patients of Group I received Clonidine (2 $\mu \mathrm{g} / \mathrm{kg})$ and patients of Group II received Nalbuphine $(0.2$ $\mathrm{mg} / \mathrm{kg}$ ), for intravenous premedication. Both drugs were diluted in $10 \mathrm{~mL}$ normal saline and administered 10 minutes before induction. Group allocation and study drug preparation was done by an assistant who was blinded to the study protocol. Neither investigator nor the observer were aware of study protocol to keep the double blindness of study.

\section{Anaesthetic Technique}

All selected patients were given tab Alprazolam $0.25 \mathrm{mg}$ and tab. Ranitidine $150 \mathrm{mg}$ orally, the night before surgery and were kept fasting for 6 hours prior to surgery. On arrival to operation theatre, all patients were placed in supine position and routine monitoring was commenced using a Multipara monitor and baseline vital parameters of heart rate, systemic blood pressure, peripheral oxygen saturation ( $\mathrm{SpO} 2)$ and electrocardiogram (ECG) were recorded. An intravenous line was secured and lactate Ringer solution was started at the rate of $4-6 \mathrm{ml} / \mathrm{kg} / \mathrm{h}$.

They were given inj. midazolam $0.02 \mathrm{mg} / \mathrm{kg}$, inj. glycopyrrolate $0.2 \mathrm{mg}$, inj. Fentanyl $100 \mu \mathrm{g}$ and inj. ondansetron $4 \mathrm{mg}$, followed by the study drug, clonidine 2 $\mu \mathrm{g} / \mathrm{kg}$ or nalbuphine $0.2 \mathrm{mg} / \mathrm{kg}$ solution, intravenously 10 minutes before induction, according to randomization schedule, in double blind manner.

After pre oxygenation for 3 min with $100 \%$ oxygen via face mask, anaesthesia was induced with propofol $2 \mathrm{mg} / \mathrm{kg}$, followed by vecuronium bromide $0.1 \mathrm{mg} / \mathrm{kg}$ to facilitate direct laryngoscopy and intubation. All patient were manually ventilated with $100 \%$ oxygen. When double burst suppression was $95 \%$ or when Train of four (TOF) was zero, the laryngoscopy was performed with Macintosh curve blade laryngoscope within a period of 15 seconds with proper sized cuffed endotracheal tube. Any patient requiring more than 20 seconds or more than one attempt for intubation, was excluded from the study. Anaesthesia was maintained with isoflurane, nitrous oxide $60 \%$ in oxygen. The patients were mechanically ventilated to keep normocapnia. The tidal volume and ventilatory frequency was adjusted to maintain EtCO2 between $35-40 \mathrm{~mm} \mathrm{Hg}$.

The hemodynamic parameters of heart rate, systemic blood pressure (systolic, diastolic and mean arterial pressure) and peripheral oxygen saturation were noted along with analysis of electrocardiogram (ECG) for any change in rhythm and ST segment. These parameters were recorded at baseline, after giving study drug, immediately after laryngoscopy and intubation, then at intervals of $1 \mathrm{st}, 3 \mathrm{rd}, 5 \mathrm{th}, 7 \mathrm{th}, 10 \mathrm{th}$ and 15 th min, after intubation. Then monitoring was continued at 5 min interval during intraoperative period till end of surgery and post extubation.

The hemodynamic changes observed as abnormal finding during the study were defined as hypotension when SBP was less than $20 \%$ of baseline value or less than $90 \mathrm{~mm} \mathrm{Hg}$, whichever was lower and hypertension when SBP was more than $20 \%$ of baseline value or more than $140 \mathrm{~mm} \mathrm{Hg}$ whichever was higher. The tachycardia was defined as heart rate more than 100 beats per min and bradycardia was defined as heart rate less than 60 beats per min.

Patients were not stimulated during the observation period and thereafter the surgery was allowed to proceed. Hemodynamic changes occurring during study period was not treated unless these changes were sustained over a period of time and were compromising patient's safety.

Intraoperatively, hypertension was managed by increasing the dial concentration of isoflurane and hypotension was treated primarily by increasing the rate of lactate Ringer infusion, decreasing the dial concentration of isoflurane and additionally with intravenous bolus of inj. mephenteramine, $6 \mathrm{mg}$. Bradycardia was managed by bolus of inj. atropine 0.6 $\mathrm{mg}$. Record of each such patient was kept.

At the end of surgery, isoflurane was discontinued and residual neuromuscular blockade was antagonized with appropriate doses of intravenous neostigmine $(0.05 \mathrm{mg} / \mathrm{kg})$ and glycopyrrolate $(0.01 \mathrm{mg} / \mathrm{kg})$. Ventilation was continued to eliminate volatile agent until signs of awaking appeared. Both the level of consciousness and neuromuscular transmission were assessed for adequacy of reflexes. Patients were extubated after sign of adequate reversal and patient were able to obey simple commands.

Any postoperative hemodynamic changes, shivering, sedation, respiratory depression, nausea and vomiting were noted and treated accordingly.

\section{Sample size}

Preliminary sample size was decided in consultation with statisticians and was based on previous studies, which indicated that approximately 27 patients should be included in each group in order to ensure power of $80 \%$ and alpha error of 0.05 with confidence limit of $95 \%$ for detecting clinically meaningful reduction by $20 \%$ in accentuated hemodynamic changes during direct laryngoscopy and intubation. Assuming a 5\% drop out rate, a total of 60 patient were incorporated in the study for better validation of results.

\section{Statistical Analysis}

The data obtained in the study was presented in a tabulated manner and variables were expressed as mean \pm standard deviation (SD), considering the later as the best predictor for 
statistical analysis. The results were analyzed using Stat graphic centurion, version 16 (Stat point technologies INC, Warrenton, Virginia). The parameters of both groups were compared using one way analysis of variance (ANOVA), Chi square test, unpaired and paired ' $\mathrm{T}$ ' test. A $\mathrm{P}$ value of less than 0.05 was considered to indicate statistical significance and $\mathrm{P}$ value less than 0.001 was considered statistically highly significant.

\section{Results}

The present study compared the clinical efficacy of intravenous clonidine with nalbuphine premedication on hemodynamic changes during direct laryngoscopy on 60 adult patients of both genders. The sample size was adequate to detect statistical significance in hemodynamic changes during direct laryngoscopy and intubation. There was no protocol deviation and data of all patients were included for statistical analysis.

Demographic parameters of age, height, weight, gender ratio and ASA physical status were comparable between the groups. [Table 1]

\section{Hemodynamic Changes}

At base line, the mean heart rate, mean systolic blood pressure, mean diastolic blood pressure, and average mean arterial pressure in patients of Group I was 85.6 \pm 6.08 beats/min, $128.87 \pm 4.36 \mathrm{mmHg}, 84.6 \pm 7.05 \mathrm{mmHg}$, and 98.96 $\pm 10.14 \mathrm{mmHg}$ respectively, while in patients of Group II, it was $89.57 \pm 7.2$ beats/min, $127.7 \pm 3.15 \mathrm{mmHg}, 85.3 \pm 6.0$ $\mathrm{mmHg}$, and $98.62 \pm 10.74 \mathrm{mmHg}$ respectively. Both the groups were comparable with no statistically significant difference. [Table 2]

After administration of clonidine $2 \mu \mathrm{g} / \mathrm{kg}$ and nalbuphine 0.2 $\mathrm{mg} / \mathrm{kg}$, the fall in mean heart rate (Group I-80.63 $\pm 67 \mathrm{~b} / \mathrm{m}$, Group II- $86.5 \pm 6.32 \mathrm{~b} / \mathrm{m}$ ) showed statistically significant difference between the both. There was fall in systolic blood pressure (Group I- $122.03 \pm 8.0 \mathrm{mmHg}$, Group II- $128.67 \pm 7.0$ $\mathrm{mmHg}$ ), diastolic blood pressure (Group I-80.9 \pm 12.49 , Group II- $83.7 \pm 11.5 \mathrm{mmHg}$ ) and mean arterial pressure (Group I-94.61 $\pm 13.11 \mathrm{mmHg}$, Group II-98.0 $\pm 10.69 \mathrm{mmHg}$ ) and the difference was statistically significant between the groups. [Table 3-5]

After induction with propofol, there was further fall in mean heart rate (Group I-74.97 $\pm 7.8 \mathrm{~b} / \mathrm{m}$, Group II- $83.4 \pm 8.4 \mathrm{~b} / \mathrm{m}$ ), systolic blood pressure (Group I-116.2 $\pm 4.32 \mathrm{~mm} \mathrm{Hg}$, Group II- $118.2 \pm 4.82 \mathrm{mmHg}$ ), diastolic blood pressure (Group I-77.9 \pm 13.36 , Group II-78.6 $\pm 10.51 \mathrm{~mm} \mathrm{Hg}$ ) and mean arterial pressure (Group I-90.66 $\pm 14.66 \mathrm{~mm} \mathrm{Hg}$, Group II- $89.8 \pm 11.92 \mathrm{~mm} \mathrm{Hg}$ ) in patients of both groups. The difference was statistically significant between the group (p $=<0.001)$. [Table 3-5]

After direct laryngoscopy and intubation, in patients of clonidine group, the increase in mean heart rate $(96.6 \pm 3.2$ $\mathrm{b} / \mathrm{m})$, systolic blood pressure $(136.8 \pm 6 \mathrm{mmHg})$, diastolic blood pressure $(89.3 \pm 8.5 \mathrm{mmHg})$, and mean arterial blood pressure $(102.17 \pm 15.06 \mathrm{~mm} \mathrm{Hg})$, occurred immediately after laryngoscopy and intubation and persisted up to 5 to $7 \mathrm{~min}$, thereafter the changes returned to baseline. [Table 3-5]

After direct laryngoscopy and intubation, in patients of nalbuphine group, the increase in mean heart rate $(112.11 \pm 5.6 \mathrm{~b} / \mathrm{m})$, systolic blood pressure $(137.2 \pm 7.68$ $\mathrm{mmHg})$, diastolic blood pressure $(91.4 \pm 10.1 \mathrm{mmHg})$, and mean arterial blood pressure $(106.6 \pm 14.32 \mathrm{~mm} \mathrm{Hg})$, occurred immediately after laryngoscopy and intubation and persisted up to $10 \mathrm{~min}$, thereafter the hemodynamic changes returned to baseline. [Table 3-5]

The difference in hemodynamic changes between the groups were statistically significant.

Table 1: Demographic profile $(n=60)$.

\begin{tabular}{|l|l|l|l|}
\hline Parameters & Group I & Group II & P Value \\
\hline Age $($ years $)$ & $46.76 \pm 12.3$ & $48.54 \pm 10.9$ & 0.07 \\
\hline Height $(\mathrm{cm})$ & $154.67 \pm 4.8$ & $153.83 \pm 5.4$ & 0.48 \\
\hline Weight $(\mathrm{kg})$ & $59.17 \pm 7.5$ & $60.23 \pm 5.3$ & 0.565 \\
\hline Gender $(\mathrm{M} / \mathrm{F})$ & $18 / 12$ & $19 / 11$ & 0.87 \\
\hline ASA (I/II) & $20 / 10$ & $21 / 9$ & 0.73 \\
\hline
\end{tabular}

Data are presented in Mean \pm SD or absolute numbers. $\mathrm{P}$ value $>0.05$ is statistically insignificant.

Table 2: Baseline Hemodynamic parameters

\begin{tabular}{|l|l|l|l|}
\hline \multicolumn{1}{|c|}{ Parameters } & \multicolumn{1}{|c|}{ Group I } & \multicolumn{1}{|c|}{ Group II } & \multicolumn{1}{c|}{ P value } \\
\hline Heart rate (beats/min) & $85.6 \pm 6.08$ & $89.57 \pm 7.2$ & 0.09 \\
\hline Systolic BP(mmHg) & $128.87 \pm 4.36$ & $127.7 \pm 3.15$ & 0.238 \\
\hline Diastolic BP $(\mathrm{mmHg})$ & $84.6 \pm 7.05$ & $82.5 \pm 6.0$ & 0.219 \\
\hline $\begin{array}{l}\text { Mean Arterial Pressure } \\
(\mathrm{mmHg})\end{array}$ & $\begin{array}{l}98.96 \\
\pm 10.14\end{array}$ & $98.62 \pm 10.74$ & 0.946 \\
\hline
\end{tabular}

Table 3: Comparison of mean Heart Rate

\begin{tabular}{|l|l|l|l|l|l|}
\hline \multirow{2}{*}{$\begin{array}{c}\text { Heart Rate } \\
\text { (beats/min) }\end{array}$} & \multicolumn{2}{|c|}{ Group I } & \multicolumn{2}{c|}{ Group II } & \multirow{2}{*}{ P value } \\
\cline { 2 - 6 } & Mean & SD & Mean & SD & \\
\hline Baseline & 85.6 & 6.08 & 89.57 & 7.2 & 0.090 \\
\hline After study drug & 80.63 & 5.67 & 86.5 & 6.32 & $* *<0.001$ \\
\hline After Induction & 74.97 & 7.8 & 83.4 & 8.54 & $*<0.05$ \\
\hline $\begin{array}{l}\text { Immediate post } \\
\text { Intubation }\end{array}$ & 96.6 & 3.2 & 112.11 & 5.56 & $*<0.05$ \\
\hline 1 min & & & & & \\
\hline 2 min & 92.2 & 4.6 & 111.6 & 5.43 & $*<0.05$ \\
\hline 3 min & 90.8 & 5.9 & 109.9 & 5.64 & $*<0.05$ \\
\hline 5 min & 90.2 & 4.6 & 107.91 & 5.66 & $*<0.05$ \\
\hline 7 min & 88.6 & 5.2 & 103.26 & 5.57 & $*<0.05$ \\
\hline 10 min & 85.3 & 6.4 & 100.97 & 6.00 & $*<0.05$ \\
\hline 15 min & 84.6 & 5.6 & 95.23 & 5.69 & $*<0.05$ \\
\hline
\end{tabular}
significant; **P value $<0.001$ is statistically highly significant.

Table 4: Comparison of mean Systolic Blood Pressure

\begin{tabular}{|c|c|c|c|c|c|}
\hline \multirow{2}{*}{$\begin{array}{l}\text { Systolic Blood Pressure } \\
(\mathrm{mm} \mathrm{Hg}) \mathrm{Mm}\end{array}$} & \multicolumn{2}{|c|}{ Group I } & \multicolumn{2}{|c|}{ Group II } & \multirow{2}{*}{$\begin{array}{c}\mathbf{P} \\
\text { value }\end{array}$} \\
\hline & Mean & SD & Mean & SD & \\
\hline Baseline & 127.7 & 4.36 & 128.87 & 3.15 & $>0.05$ \\
\hline After study drug & 122.03 & 8.0 & 128.67 & 7.0 & $*<0.05$ \\
\hline After Induction & 116.2 & 4.32 & 118.2 & 4.82 & $* 0.047$ \\
\hline Immediate post Intubation & 136.8 & 6.0 & 137.2 & 7.68 & $* 0.038$ \\
\hline $1 \mathrm{~min}$ & 136.3 & 5.6 & 136.4 & 8.2 & $* 0.023$ \\
\hline $2 \min$ & 132.3 & 4.6 & 135.2 & 6.43 & $* 0.011$ \\
\hline $3 \mathrm{~min}$ & 132.2 & 4.5 & 134.9 & 4.42 & $* 0.023$ \\
\hline $5 \mathrm{~min}$ & 131.3 & 4.4 & 134.7 & 3.98 & $* 0.05$ \\
\hline $7 \mathrm{~min}$ & 128.7 & 5.6 & 132.3 & 4.4 & $*<0.05$ \\
\hline $10 \min$ & 126.3 & 6.0 & 130.6 & 2.75 & $*<0.05$ \\
\hline $15 \mathrm{~min}$ & 118.43 & 3.6 & 127.34 & 3.20 & $*<0.05$ \\
\hline
\end{tabular}

\begin{tabular}{|l|l|l|l|l|l|}
$15 \mathrm{~min}$ & 118.43 & 3.6 & 127.34 & 3.20 & $*<0.05$ \\
\hline Data are presented in Mean \pm SD or absolute numbers. ${ }^{*} \mathrm{P}$ value $<0.05$ is statistically
\end{tabular} significant.

\section{Complications during study}

Five patients of clonidine Group I developed hypotension and two patient showed heart rate $<60$ beats/min. It occurred after premedication but heart rate and blood pressure increased after laryngoscopy and intubation. Hence no 
medical intervention was required. No other complications related to study drug or anesthetic technique occurred during the study period.

\begin{tabular}{|c|c|c|}
\hline \multicolumn{3}{|c|}{ Table 5: Comparison of mean Diastolic Blood Pressure } \\
\hline \multirow{2}{*}{$\begin{array}{c}\begin{array}{c}\text { Diastolic Blood Pressure } \\
(\mathrm{mm} \text { of } \mathrm{Hg})\end{array} \\
\end{array}$} & \multicolumn{2}{|c|}{ Group I } \\
\hline & Mean & SD \\
\hline Baseline & 84.6 & 7.05 \\
\hline After study drug & 80.9 & 12.49 \\
\hline After Induction & 76.9 & 13.36 \\
\hline Immediate post Intubation & 89.3 & 8.5 \\
\hline $1 \mathrm{~min}$ & 88.07 & 7.0 \\
\hline $2 \min$ & 86.9 & 11.3 \\
\hline $3 \min$ & 85.7 & 12.9 \\
\hline $5 \mathrm{~min}$ & 85.3 & 11.3 \\
\hline $7 \mathrm{~min}$ & 84.6 & 13.3 \\
\hline $10 \mathrm{~min}$ & 84.2 & 10.7 \\
\hline $15 \mathrm{~min}$ & 82.3 & 11.51 \\
\hline
\end{tabular}

Table 6: Comparison of average Mean Arterial Pressure

\begin{tabular}{|l|l|l|l|r|c|}
\hline \multirow{2}{*}{$\begin{array}{c}\text { Mean arterial } \\
\text { pressure (mm of Hg) }\end{array}$} & \multicolumn{2}{|c|}{ Group I } & \multicolumn{2}{c|}{ Group II } & \multirow{2}{*}{$\begin{array}{c}\text { Prolue } \\
\text { value }\end{array}$} \\
\hline Baseline & Mean & SD & Mean & SD & 0.946 \\
\hline After study drug & 98.96 & 10.14 & 98.62 & 10.74 & 0.040 \\
\hline After Induction & 94.61 & 13.11 & 98.0 & 10.69 & $* 0.049$ \\
\hline $\begin{array}{l}\text { Immediate post } \\
\text { Intubation }\end{array}$ & 90.66 & 14.66 & 89.8 & 11.92 & $* 0.047$ \\
\hline 1 min & 102.1 & 15.06 & 106.6 & 14.32 & 0.051 \\
\hline 2 min & 7 & & & & \\
\hline 3 min & 100.6 & 16.14 & 105.4 & 14.05 & $*<0.05$ \\
\hline 5 min & 98.9 & 15.11 & 104.2 & 14.26 & $*<0.05$ \\
\hline 7 min & 96.2 & 13.41 & 103.2 & 12.62 & $*<0.05$ \\
\hline 10 min & 93.6 & 12.53 & 103.2 & 12.02 & $*<0.05$ \\
\hline 15 min & 92.4 & 15.57 & 101.3 & 11.65 & $*<0.05$ \\
\hline
\end{tabular}

Data are presented in Mean \pm SD or absolute numbers. $*$ P value $<0.05$ is statistically significant.

\section{Discussion}

Direct laryngoscopy and intubation is most noxious stimuli during airway management due to intense sympathetic discharge and release of catecholamine, which manifested as hypertension and tachycardia. These short lived hemodynamic changes can be harmful in patients with preexisting myocardial disease or cerebral insufficiency. If no specific measures are taken to prevent these hemodynamic changes, the cardiac work load may be increased which in turn may terminate in perioperative myocardial ischemia or acute heart failure. Surgical stress also leads to increase catecholamine release which can further intensify the intraoperative hemodynamic instability.

The therapeutic armamentarium to counteract the hemodynamic changes during laryngoscopy and intubation includes a wide variety of drugs, technique and route of administration. Out of various approaches, the pharmacological approach is considered to be the best, which include high dosages of opioid analgesics, $\alpha-2$ adrenergic agonist, beta adrenergic blockers and vasodilators but with their own limitations.

In the present study, clinical efficacy of intravenous clonidine versus nalbuphine premedication was compared for hemodynamic changes during direct laryngoscopy and intubation. The significance of the study lies in the fact to select the better drug for premedication which could reduce the hemodynamic changes during direct laryngoscopy and intubation. Besides minimizing the haemodynamic changes, premedication must be applicable regardless of the patient group, prevent impairment of cerebral blood flow and avoid awareness during anaesthesia. Drugs should be such that they do not affect the duration or modality of the anaesthetic technique and should not effects the recovery profile of the patient.

Not many studies have been done to compare the clinical efficacy of intravenous clonidine with nalbuphine premedication for reduction of haemodynamic changes during direct laryngoscopy and intubation, therefore these premedicants were selected for the present study.

Clonidine is alpha-2 agonists and showed pharmacological effects on blood pressure and heart rate, due to its sympathoinhibitory action. It has analgesic, sedative and anxiolytic profile. Antinociceptive action of clonidine exits for both somatic and visceral pain. These properties along with its ability to maintain intra-operative hemodynamic stability make clonidine a useful adjuvant in anaesthesia and intensive care. $^{[7]}$

Nalbuphine is an agonist-antagonist opioid analgesic causes less respiratory depression by activating the supraspinal and spinal kappa receptor. It does not allow increase in systemic blood pressure, pulmonary blood pressure, heart rate, thus may be useful for providing sedation and analgesia for cardiac patients. ${ }^{[8,9]}$

The selection of dosages for the present study was based on the assumption that which almost equipotent doses could supress the hemodynamic changes with minimal side effects. For the present study, clonidine in dose of $2 \mu \mathrm{g} / \mathrm{kg}$ and nalbuphine in dose of $0.2 \mathrm{mg} / \mathrm{kg}$ were selected for intravenous premedication.

In the present study, there was significant rise of heart rate in patients of nalbuphine group immediately after intubation till 10 min while in patients of clonidine group, the rise in heart rate was till $3 \mathrm{~min}$ only. These changes in heart rate were statistically highly significant.

Jiwanmall $\mathrm{M}$ et al used intravenous clonidine in the dose of 3 $\mu \mathrm{g} / \mathrm{kg}$ and found that target mean arterial pressure could be achieved easily in clonidine group as against the placebo group with significant reduction in intra-operative blood loss with good analgesia. ${ }^{[10]}$ In another study, done by Deepshikha C Tripathi et al, it was observed that clonidine in dose of $2 \mu \mathrm{g} / \mathrm{kg}$ prevented the hemodynamic stress response that associated with intubation and extubation. ${ }^{[11]}$

Clonidine, $\alpha 2$-adrenoreceptors agonist, has potent analgesic and sedative effect with a low side effect profile and low abuse potential. It decreases discharge in sympathetic preganglionic fibres in the splanchnic nerve and in postganglionic fibres of cardiac nerves and stimulates the parasympathetic outflow, which may contribute to the slowing of heart rate as a consequence of increased vagal tone and diminished sympathetic drive. In addition, some of the antihypertensive effects of clonidine may be mediated by activation of presynaptic alpha 2 receptors that supress the release of norepinephrine, ATP and NPY from postganglionic sympathetic nerves.

In the present study, as increase in mean systolic blood 
pressure, mean diastolic blood pressure and mean arterial pressure was observed in patients of both groups and these changes showed statistically significant difference from the baseline after laryngoscopy and intubation. The rise was highest in patients of nalbuphine group immediately after laryngoscopy and intubation.

Priti M Chawda et al studied the efficacy of nalbuphine in preventing the increase in heart rate and mean arterial pressure in response to laryngoscopy and intubation. They observed significant rise in heart rate in the control group (20.4\%) after intubation at 2 min when compared to nalbuphine group $(16.66 \%)$. Heart rate and mean arterial pressure gradually decreased after 3 to $8 \mathrm{~min}$ in control group but always remained higher than patient of nalbuphine group, thus concluded that nalbuphine attenuated the hemodynamic response to laryngoscopy and intubation. ${ }^{[12]}$

Similar results were found by Chaudhari $\mathrm{M}$ et al, showing increase in mean heart rate and increase in systolic blood pressure in patients of nalbuphine group which was statistically highly significant compared to clonidine group, immediately after intubation. The increase in diastolic blood pressure and mean arterial pressure in nalbuphine group was statistically significant when compared to clonidine group immediately after intubation and then after at $1,3,5,7,10$ min and 15 min after intubation. ${ }^{[13]}$

Nath $\mathrm{R}$ et al concluded in their study that nalbuphine $(0.2$ $\mathrm{mg} / \mathrm{kg}$ ) produced stable hemodynamics during stressful period of laryngoscopy and intubation by virtue of its reduction in pulse rate, systolic blood pressure and diastolic blood pressure with fewer adverse effects and good analgesia. ${ }^{[14]}$

Bhalerao PM et al observed that intraoperative mean pulse rate was $90.82 \pm 4.81$ beats/min in control group while it was $74.76 \pm 9.88$ beats/min in clonidine group. The mean systolic blood pressure was $137.87 \pm 4.89$ and $125.79 \pm 6.44 \mathrm{mmHg}$ respectively. They concluded that premedication with intravenous clonidine is effective method to provide stable hemodynamics and protection against stress response induced during laparoscopic cholecystectomy. ${ }^{[15]}$

Ray M, Bhattacharjee DP et al concluded in their study that immediately after laryngoscopy and intubation, heart rate increased by $10 \mathrm{bpm}$ in patients of clonidine group, while mean arterial pressure in clonidine group decreased significantly for all measurements with the exception during intubation and after induction. ${ }^{[16]}$

Altan A et al studied clonidine in dose of $3 \mu \mathrm{g} / \mathrm{kg}$ and found that, mean arterial pressure increased by $16 \mathrm{~mm} \mathrm{Hg}$ in control group, whereas in clonidine group, the mean arterial pressure increased only by $10 \mathrm{mmHg}$, which showed clonidine has significant blunting effect of pressor response of laryngoscopy and intubation. ${ }^{[17]}$ The present study also observed that clonidine effectively reduced the hemodynamic changes.

The primary objective of the present study was to comparatively evaluate the clinical efficacy of intravenous clonidine versus nalbuphine premedication on hemodynamic changes during laryngoscopy and intubation in normotensive patients. The findings of present study were in consistence with these previous clinical studies. Based on the results of the present study and the above discussion, intravenous clonidine and nalbuphine, both offered a unique pharmacological profile with sedation, analgesia and intraoperative cardiovascular stability. Clonidine and nalbuphine, both has attenuated but did not abolish the hemodynamic responses to laryngoscopy and intubation.

\section{Conclusion}

Intravenous premedication with clonidine or nalbuphine, could reduce the hemodynamic changes by altering the stress induced sympatho-adrenal responses to direct laryngoscopy and intubation with inherent advantage of analgesia and sedation. Clonidine $(2 \mu \mathrm{g} / \mathrm{kg})$ was more effective in reducing the hemodynamic changes of laryngoscopy and intubation than nalbuphine $(0.2 \mathrm{mg} / \mathrm{kg})$, when administered as premedication 10 minute before induction.

\section{Limitation of study}

1. The dose of propofol required for induction of anesthesia for each patient could have been assessed as clonidine and nalbuphine, both causes sedation.

2. The intraoperative isoflurane concentration could have also been assessed for each patient as clonidine and nalbuphine, both leads to sedation and analgesia.

3. Intraoperative Bispectral Index (BIS) monitoring would have been more objective in deciding the depth of anesthesia.

4. Control group could not be included due to ethical reasons.

\section{References}

1. Freye E, Levy JV. Reflex activity caused by laryngoscopy and intubation is obtunded differently by meptazinol, nalbuphine and fentanyl. Eur J Anaesthesiol 2007;24:53-8.

2. Isaac L. Clonidine in the central nervous system: site and mechanism of hypotensive action. J Cardiovasc Pharmacol. 1980;2 Suppl 1:S5-19.

3. Giovannitti JA, Thomas SM, Crawford JJ. Alpha-2 adrenergic receptors agonist: a review of current clinical applications. Anesth Prog 2015;62:31-8.

4. Haq AU, Kazmi EH, Rao ZA. Nalbuphine prevents haemodynamic response to endotracheal intubation. J Coll Physicians Surg Pak 2005;15:668-70.

5. Kothari D, Sharma CK. Effect of nalbuphine and pentazocine on attenuation of hemodynamic changes during laryngoscopy and endotracheal intubation: A clinical study. Anaes Essays Res 2013;7:326-30

6. Tariq AM, Iqbal Z, Qadirullah. Efficacy of nalbuphine in preventing haemodynamic response to laryngoscopy and intubation. J Postgrad Med Inst 2014;28:211-6.

7. Arora S, Kulkarni A, Bhargava AK. Attenuation of hemodynamic response to laryngoscopy and orotracheal intubation using intravenous clonidine. Journal of Anaesthesiol Clin Pharmacol 2015;31:110-4.

8. Dabhi P, Mehta S. Effect of intravenous nalbuphine on hemodynamic response to laryngoscopy and intubation. Int J Res Med 2014;3:24-7

9. Fating D, Dandekar A, Tirpude A. Role of intravenous Nalbuphine in attenuation of haemodynamic response to laryngoscopy and endotracheal intubation. Journal of Clinical Anaesthesia 2016;3:16569.

10. Jiwanmall M, Joselyn AS, Kandasamy S. Intravenous clonidine as a part of balanced anaesthesia for controlled hypotension in functional endoscopic sinus surgery: A randomized controlled trial. Indian J Anaesth 2017;61:418-23.

11. Deepshikha C Tripathi, Komal S Shah, Santosh R Dubey, Shilpa M Doshi, Punit V Raval. Hemodynamic stress response during laparoscopic cholecystectomy: Effect of two different doses of intravenous clonidine premedication. J Anaesthesiol Clin Pharmacol 2011; $27: 475-80$. 
12. Priti M Chawda, Mayuresh K Pareek, Ketan D Mehta. Effect of Nalbuphine on Haemodynamic Response to Orotracheal Intubation. J Anaesth Clin Pharmacol 2010;26:458-60.

13. Chaudhari M.J, Bhatia U, Patel N, Patel K. Efficacy of nalbuphine in preventing hemodynamic response to laryngoscopy and intubation in comparison to clonidine. NHL Journal of Medical Science 2015;4: 5864.

14. Nath R, Dutta S, Khandelwal A. Attenuation of Hemodynamic Response during Laryngoscopy and Intubation with Low Dose Intravenous Nalbuphine. J Hematol Transfus 2015;3(5):1036-9.

15. Bhalerao PM, Thombre SK, Kapse US, Targe KV. Intravenous clonidine for suppression of haemodynamic response to laparoscopy-a prospective randomised, placebo controlled, single centre study. Int $\mathbf{J}$ Adv Med 2017;4:788-92.

16. Ray M, Bhattacharjee DP, Hajra B, Pal R. Effect of clonidine and magnesium sulphate on anaesthetic consumption, haemodynamics and postoperative recovery: A comparative study. Ind J Anaesth 2010; 54:137-41.

17. Altan A, Turgut N, Yildiz F, Turkmen A, Ustiin H. Effects of magnesium sulphate and clonidine on propofol consumption, haemodynamics and post-operative recovery. British Journal of Anaesthesia 2005;93:438- 41 .

Copyright: (C) the author(s), publisher. Academia Anesthesiologica International is an Official Publication of "Society for Health Care \& Research Development". It is an open-access article distributed under the terms of the Creative Commons Attribution Non-Commercial License, which permits unrestricted non-commercial use, distribution, and reproduction in any medium, provided the original work is properly cited.

How to cite this article: Bansal MK, Gupta K, Kumar A, Agarwal S, Sharma D, Baseer AM. Reduction in Hemodynamic Changes during Direct Laryngoscopy and Intubation by Intravenous Clonidine or Nalbuphine Premedication - A Comparative Evaluation. Acad. Anesthesiol. Int. 2018;3(2):1-6.

DOI: dx.doi.org/10.21276/aan.2018.3.2.1

Source of Support: Nil, Conflict of Interest: None declared. 